\title{
El HACCP y la ISO 22000: Herramienta esencial para la inocuidad y calidad de los alimentos
}

\section{INTRODUCCIÓN}

El conocimiento del manejo de los alimentos fue, es y será muy importante en el día a día del ser humano. Los alimentos son de origen animal, vegetal y mineral. En los dos primeros casos son de fácil deterioro, lo que hace necesario que se tomen precauciones para que se consuman alimentos inocuos. En el tercer caso, la contaminación se da por la presencia de materiales extraños mezclados con el producto original, que no permitiría su consumo.

En los inicios del hombre, la calidad de los alimentos se evaluaba por los sentidos, como la vista, el tacto, el gusto, el olfato o por combinaciones de ellos; luego se medían algunas características y en función de ellas se evaluaba su calidad. En la actualidad existen sistemas de calidad como el HACCP y la ISO 22000 que aseguran tanto la inocuidad como la calidad de los alimentos.

\section{LOS ALIMENTOS}

Para conocer acerca de la inocuidad y calidad de los alimentos debemos conocer algo más sobre estos. Una forma sencilla de aprender 
qué componentes contienen es utilizando el diagrama causa-efecto, el cual se ha adaptado al tema sustituyendo lo que es el peligro por el alimento y las causas por los componentes. En el gráfico 1 se muestra el diagrama causa-efecto de la composición química de un alimento. Los porcentajes en el rango de los componentes se aproximan a los más representativos de origen animal y vegetal.

\section{Gráfico 1 \\ Composición de los alimentos}
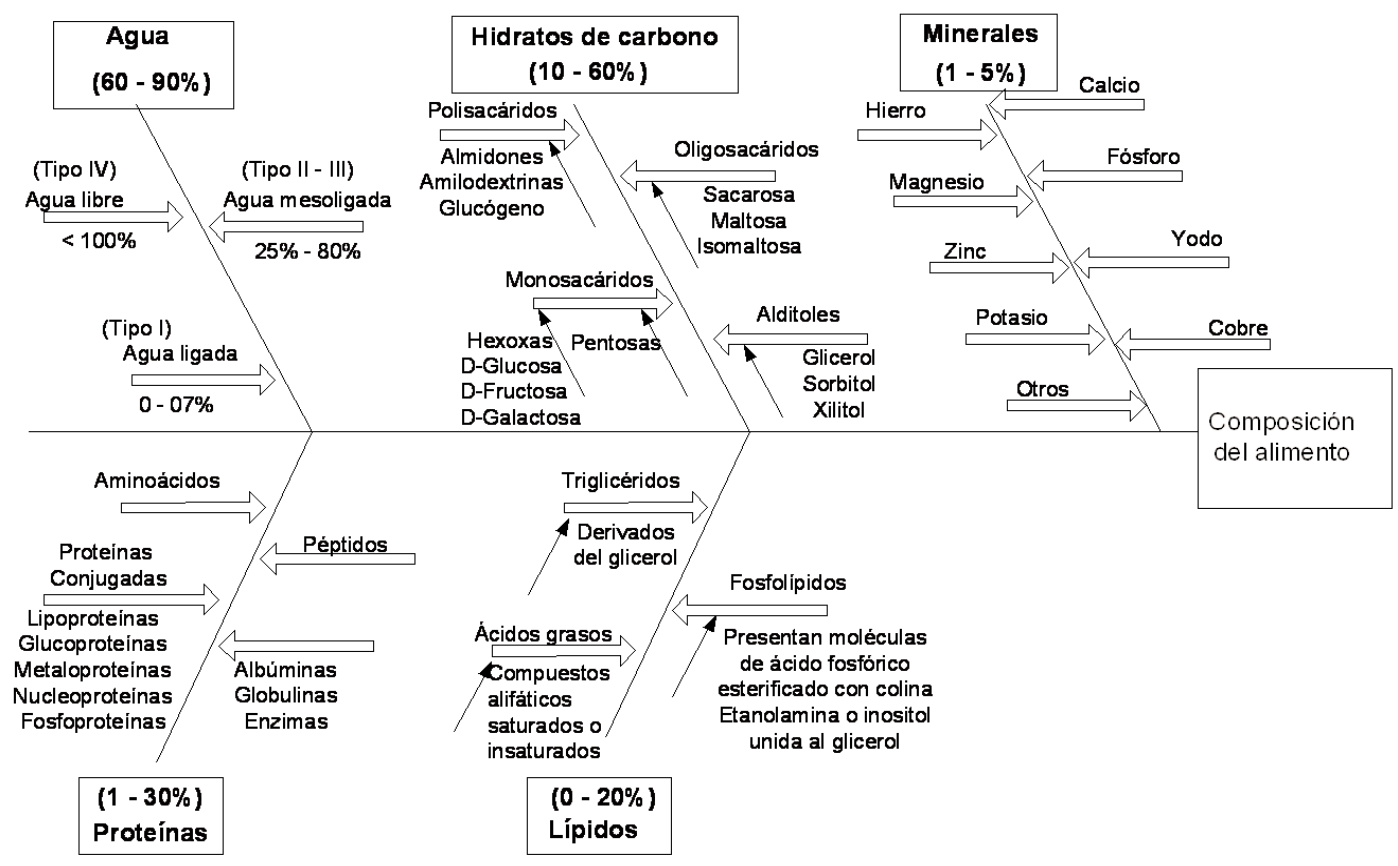

La composición de los alimentos depende de si son de origen animal o vegetal. En el caso de los de origen animal predominan las proteínas y las grasas y en los de origen vegetal los carbohidratos. Esto no quiere decir que no tengan cantidades variables de agua, grasas, proteínas, minerales y carbohidratos.

Así también, si queremos saber cómo contrarrestar los problemas de descomposición de los alimentos debemos conocer qué factores causan principalmente este efecto. En el gráfico 2 se muestran las causas de la descomposición de los alimentos. 


\section{Gráfico 2}

Factores de descomposición de los alimentos

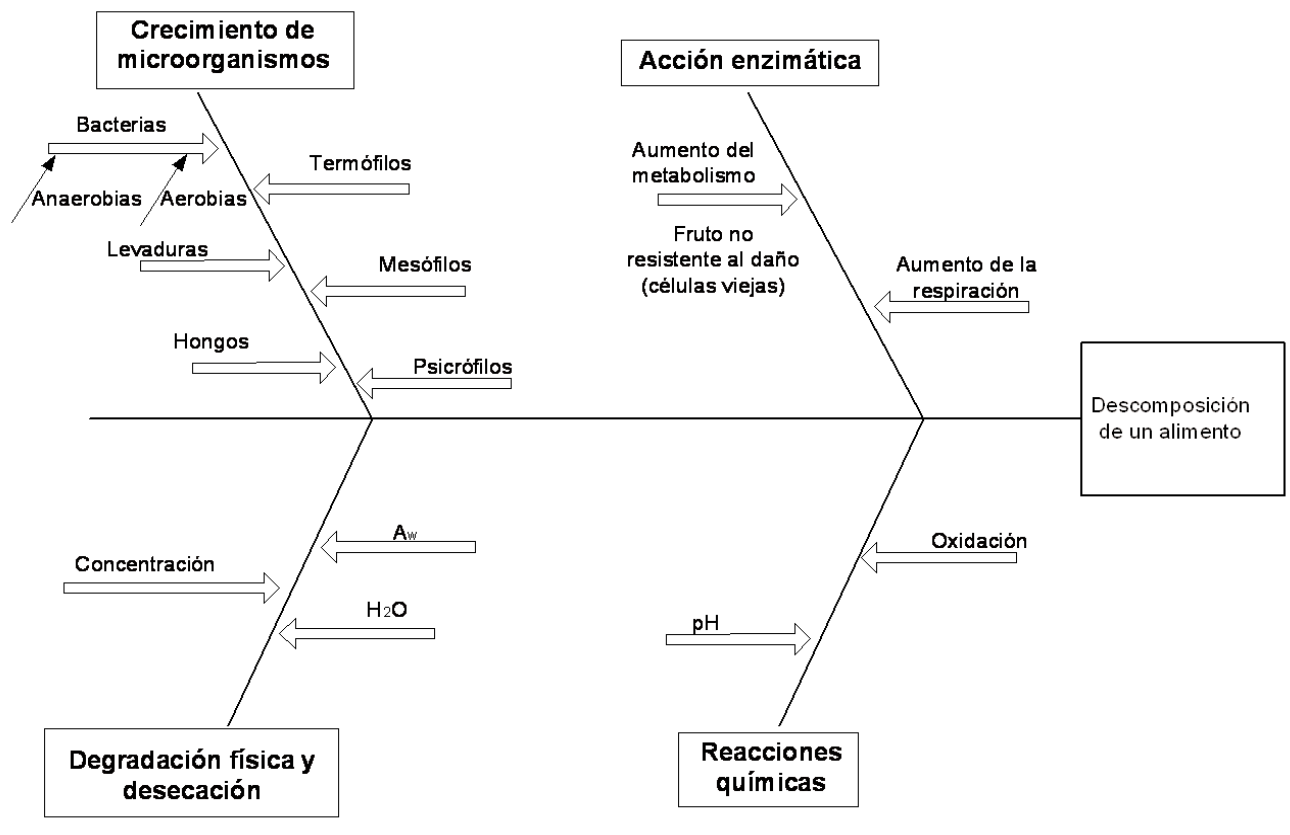

Como se puede ver, el propio metabolismo del alimento como su acción enzimática y las reacciones químicas son aceleradas por una acción externa de temperatura o humedad. Así también, el proceso de descomposición se puede ver acelerado o retardado por la acción de los microorganismos.

Es por ello que el hombre en el tiempo ha venido buscando formas de conservar el alimento de manera que pueda utilizarlo cuando él lo necesite. En el gráfico 3 se muestran diversas formas de conservación de los alimentos.

Entre las formas de conservación tenemos la deshidratación, que busca disminuir el agua disponible para el crecimiento de microorganismos; el salado, que disminuye el contenido de agua y tiene poder bactericida; el ahumado, que además de disminuir la humedad del alimento, según se realice en caliente o frío, tiene los fenoles y aldehídos del humo, que dan una acción de conservación. En cuanto a las conservas, estas basan su conservación en la eliminación del aire por medio del evacuado y el aislamiento del alimento en un envase, que luego 
es cerrado herméticamente y sometido a un tratamiento térmico. Existen otros procesos como el marinado, que basa su conservación en la precocción, contenido de sal, el pH del vinagre que utiliza y el cerrado hermético. Existe asimismo el refrigerado y el congelado, que conservan el alimento por la temperatura cercana a cero centígrados o por debajo de esta, lo que permite que se congele el agua e impida o retarde el crecimiento de bacterias. Otro método es la irradiación, que consiste en eliminar los microorganismos con rayos de onda corta.

\section{Gráfico 3 \\ Métodos de conservación de los alimentos}

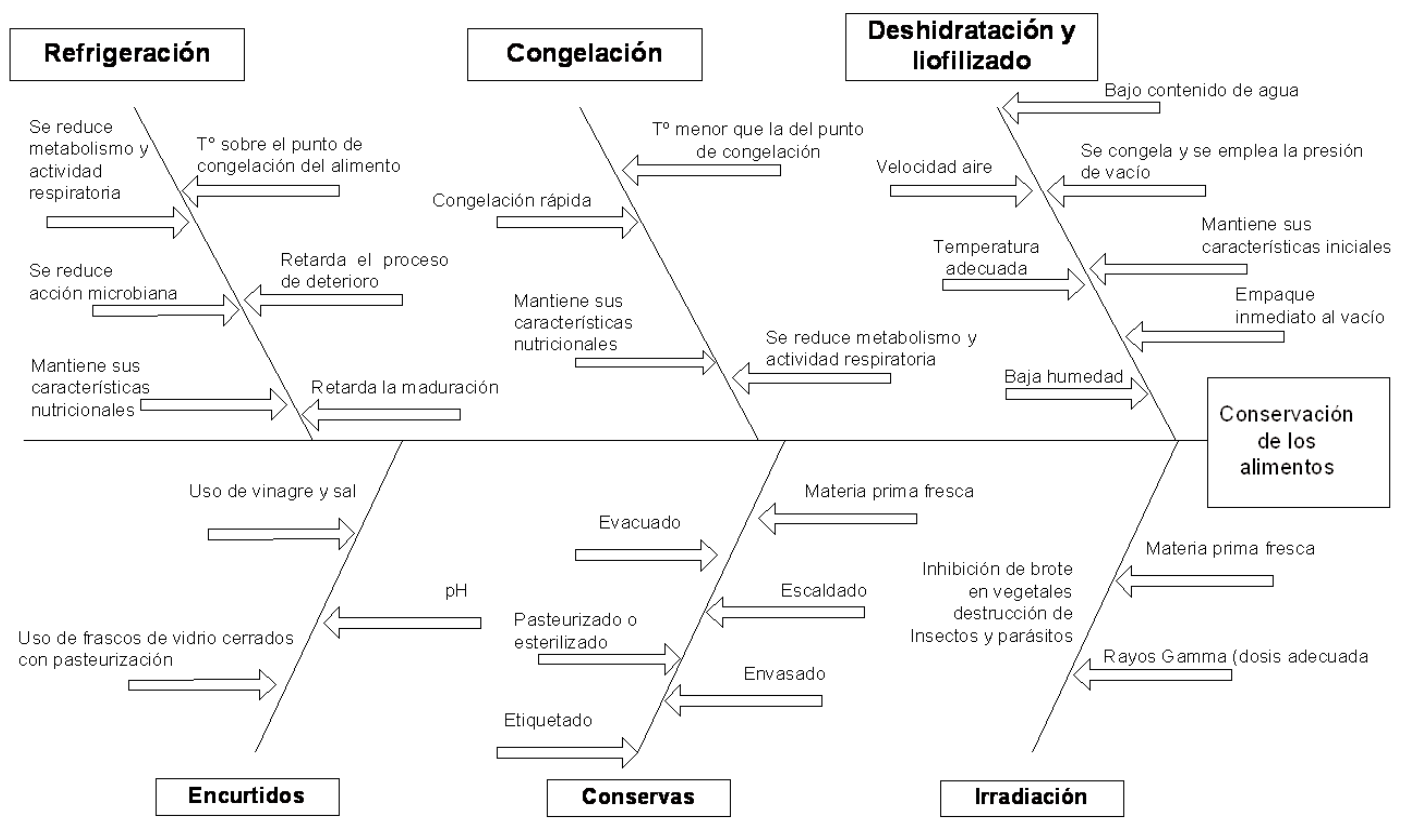

\section{EL CODEX}

El Codex Alimentarius (Código alimentario) es una colección de patrones para alimentos que se presentan de manera uniforme. La Comisión del Codex Alimentarius (CAC) fue creada en 1962 por decisión de la Organización de las Naciones Unidas para la Agricultura y la Alimentación (FAO) y la Organización Mundial de la Salud. En el Perú está representado por el Comité Nacional del Codex, creado en 1998, donde participan la Dirección General de Salud (Digesa), el Servicio 
Nacional de Sanidad Agraria (Senasa), el Servicio Nacional de Sanidad Pesquera (Sanipes), la Asociación Peruana de Consumidores y Usuarios (Aspec). En junio de 1997, el Codex Alimentarius adoptó tres nuevos textos básicos revisados sobre higiene de los alimentos:

- El Código Internacional Recomendado de Prácticas: Principios generales de higiene de los alimentos.

- El Sistema de Análisis de Peligros y de Puntos Críticos de Control (HACCP, por sus siglas en inglés) y directrices para su aplicación.

- Principios para el establecimiento y la aplicación de criterios microbiológicos para alimentos.

Entre los objetivos del Codex se cuentan:

- Identificar los principios básicos esenciales de higiene de los alimentos aplicables a lo largo de toda la cadena alimentaria.

- Recomendar la aplicación del denominado Hazard Analysis and Critical Control Points (HACCP) [análisis de peligros y puntos críticos de control], para elevar el nivel de inocuidad alimentaria.

- Indicar cómo fomentar la aplicación de esos principios.

- Facilitar la orientación para códigos (o normas) específicos.

\section{EL HACCP Y LA SEGURIDAD ALIMENTARIA}

El propósito del HACCP es ayudar a garantizar la producción de un alimento seguro. La meta de HACCP es prevenir y minimizar los riesgos asociados con agentes biológicos, químicos y físicos hasta niveles aceptables. Se basa en prevenir más que en detectar los agentes de riesgo.

¿Por qué calidad y seguridad en alimentos? Porque elimina productos insanos, reduce los costos de calidad (prevención y evaluación) y los costos de no calidad (fallas internas/externas). Asimismo, permite la fidelidad de clientes, la oportunidad de comercio internacional, mantiene la buena imagen del producto/compañía y mejora la productividad (ver gráfico 4). 


\section{Gráfico 4 \\ Cadena alimentaria}

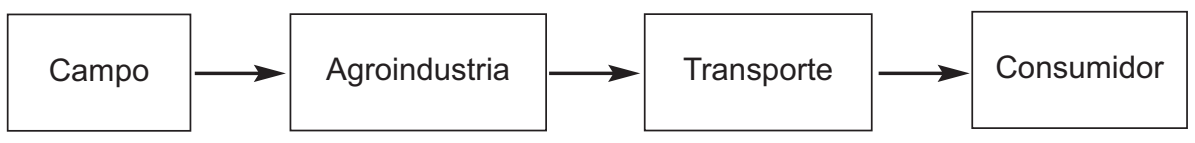

La calidad se va creando a lo largo de la cadena agroalimentaria

El productor que no elabora bien sus productos se ve perjudicado por la pérdida del mercado, la devolución del producto, el cierre permanente o temporal de la fábrica, las demandas, los despidos por reducción de volúmenes de producción, las multas o la prisión si se comprueba negligencia.

El HACCP se pone en práctica en la década de 1960 y fue utilizado por primera vez en los programas del espacio: Pillsbury y NASA, adoptado por muchos procesadores de alimentos y por el gobierno de los Estados Unidos de América. Es una estrategia del campo a la mesa en los sectores agricultura, transporte, preparación y manipulación de alimentos, procesamiento de alimentos con las regulaciones para productos cárnicos, avícolas y marinos y, finalmente, en los servicios de alimentación, uso y manejo por parte del consumidor.

En Estados Unidos existen regulaciones como el United States Departament of Agriculture (USDA-HACCP) para procesamiento de carnes y aves: Pathogen Reduction Act; las regulaciones de la Food and Drug Administration (FDA-HACCP) para inspección de productos marinos; los requisitos de la FDA para jugos de frutas sin tratamiento térmico, entre otros.

En el Perú existe un Reglamento sobre Vigilancia y Control Sanitario de Alimentos y Bebidas, aprobado por Decreto Supremo 007-98SA. Y más recientemente contamos con el proyecto Norma Sanitaria sobre el Procedimiento para la Aplicación del Sistema HACCP en la Fabricación de Alimentos y Bebidas (prepublicado con Resolución Ministerial 482-2005/Minsa el 29 de junio del 2005).

El HACCP se basa en el monitoreo de los PCC: dispositivos de tiempo/temperatura, por lo que se utilizan termómetros calibrados, dispositivos de separación, como filtros y tamices. 
El HACCP mantiene registros en los que se consideran preguntas como: ¿quién registra la información?, ¿con qué frecuencia?, ¿qué se hace si la información no es la que debe ser?, ¿quién revisa la información?

\subsection{Los principios del HACCP}

Se pueden enumerar los siguientes:

- Identificar los agentes de riesgo.- Un análisis de peligros con fallas conducirá a un plan HACCP inadecuado. Se requiere experiencia técnica para identificar apropiadamente los peligros, así como un conocimiento profundo del producto y del proceso. Se realiza para cada tipo de producto y proceso; se deben incluir los nuevos productos. Deben considerarse cambios posteriores en productos y procesos, así como prácticas de personal. Entre los peligros biológicos y los controles se encuentran los que están relacionados con bacterias, virus y parásitos. El enfoque del HACCP es sobre peligros biológicos. Según las estadísticas, las personas afectadas por las enfermedades transmitidas por alimentos van de 12 a 80 millones por año; muchas veces se producen casos de intoxicación como gripes ligeras o malestares estomacales. Aproximadamente el 0,01\% de intoxicaciones produce la muerte.

- Determinar los puntos críticos de control (PCC).- La pérdida de control de cualquier aspecto en un sistema de producción de alimentos puede ser un riesgo inaceptable para la salud; por ello, es fundamental que se determinen los puntos críticos.

- Determinar los límites críticos de seguridad para los PCC.- Deben existir una o más tolerancias preescritas que se deben cumplir para asegurar que un PCC controle efectivamente los riesgos microbiológicos, químicos o físicos para la salud. Hay referencias que nos ayudan a contestar: historia del producto, reclamos de mercado, base de datos del gobierno, literatura científica, modelos predictivos.

- Monitorear los PCC.- Un límite fuera de control hace que el PCC esté fuera de control y un PCC sin control es una desviación crítica. A su vez, una desviación crítica genera un producto inseguro. Una supervisión efectiva elimina desviaciones críticas. Los procedimientos de control de los PCC deben ser rápidos, con medidas físicas, químicas y visuales. 
- Procedimiento de desviaciones (acciones correctivas).- Los procedimientos para desviaciones son acciones correctivas predeterminadas y documentadas que están consignadas en el Manual HACCP. Las acciones correctivas están predeterminadas para que el operario responsable del PCC realice la acción siempre de igual manera. La responsabilidad de las acciones correctivas le corresponde al Departamento de Producción, que cuenta con la cooperación del área de Aseguramiento de Calidad y Gerencia.

- Verificar que el sistema está funcionando.- Auditar un sistema HACCP produce beneficios como la evidencia de debida diligencia; la revisión objetiva de la efectividad del sistema; el mantenimiento de la confianza; la identificación de las áreas de mejoramiento; el reforzamiento de los conocimientos de seguridad de alimentos y la eliminación de los mecanismos innecesarios de control.

- Registro de datos.- Los tipos de archivos que se deben guardar son el plan HACCP completo, la historia de las modificaciones, los registros de control de los PCC (desviaciones y acciones), las retenciones y reclamos de mercado, el entrenamiento, las auditorías, las actas de reuniones y la calibración.

Las directrices para la aplicación del sistema HACCP dice a la letra: "antes de aplicar el sistema de HACCP a cualquier sector de la cadena alimentaria, el sector deberá estar funcionado de acuerdo con los Principios Generales de Higiene de los Alimentos del Codex, los códigos de prácticas del Codex pertinentes y la legislación correspondiente en materia de inocuidad de los alimentos...".

Para que un sistema HACCP sea exitoso, todos los participantes deben comprometerse con el desarrollo del sistema y la elaboración del producto; deben haber evidencias objetivas de la seguridad de los productos (registros) y se debe implementar un sistema eficaz para responder las quejas de los clientes.

\subsection{Buenas prácticas de manufactura (BPM)}

Son prácticas genéricas para cualquier producto y pueden aplicarse en cualquier fábrica donde se manufacturen los productos. Son obligatorias y constituyen un requisito para el sistema HACCP. Esto guarda relación con los procesos productivos en planta y su objetivo se enfoca 
en dos elementos primordiales: evitar la contaminación y evitar errores y confusiones. Las BPM en el sector de alimentos son socias del HACCP en la preservación y mantenimiento de la inocuidad.

\subsection{Procedimientos operacionales de limpieza y desinfección (SSOP)}

El programa de SSOP es parte de las BPM e incluye: procedimientos de limpieza y desinfección que se deben seguir antes, durante y después de las operaciones; frecuencia para la ejecución de cada procedimiento e identificación del responsable de dirigirlo; vigilancia diaria de la ejecución de los procedimientos, y evaluación de la efectividad; los SSOP y sus procedimientos para la prevención de la contaminación así como la toma de acciones correctivas cuando se determina que los procedimientos no logran prevenir la contaminación.

\subsection{Etapas de implementación de un sistema HACCP}

- Formar el equipo de trabajo del HACCP.- El equipo debe ser multidisciplinario, formado por personas que estén familiarizadas con los productos y los procesos de elaboración de la planta. Deben comprender los conceptos del HACCP y conocer las etapas por cumplir para desarrollar el sistema. Deben contar con una formación que les permita identificar peligros, anticipar problemas e implementar cambios en el proceso y los productos.

- Descripción del producto.- Se debe realizar una completa descripción del producto elaborado y terminado en la planta, incluyendo la formulación, con la finalidad de realizar una evaluación sistemática de todos los peligros asociados a ese alimento y sus ingredientes (producto, composición, características fisicoquímicas, tratamientos y tipo y grado de elaboración, presentación final, almacenamiento, distribución, forma de consumo y vida útil del producto).

- Descripción del uso presunto.- Se debe detallar el uso normal o previsto que el consumidor hará del producto y luego definir el segmento de la población al que está destinado, indicando las consecuencias, si las tuviera, para aquellos consumidores sensibles al producto o a algún ingrediente.

- Elaboración del diagrama de flujo o de bloques.- Consiste en detallar en forma sucesiva todo el proceso de elaboración; se deben representar todos los pasos operacionales del manejo del producto a 
través de la planta; debe ser fácil de seguir y representar exactamente el proceso.

- Verificación in situ del diagrama de flujo.- Se debe realizar la verificación in situ de la precisión del diagrama construido en la etapa anterior. Esta verificación debe hacerse durante las horas de producción; la verificación permite corregir el diagrama sobre el documento y sobre el proceso operativo.

- Análisis de peligros y evaluación de riesgos.- El análisis de peligros se basa en la determinación de todas aquellas actividades y condiciones que constituyan riesgos potenciales y, por lo tanto, puedan afectar adversamente al producto, provocando problemas de tipo microbiológico o fisicoquímico. Las fuentes de peligros más comunes son: calidad de la materia prima, almacenamiento inadecuado (Temperatura, humedad relativa, etcétera), mala manipulación, proceso de preparación, sanidad e higiene del personal y de los ambientes y equipos.

- Determinación de los PCC.- Los puntos críticos de control son etapas del proceso donde la falta de control constituye un riesgo inaceptable para la salud del consumidor, que puede ser prevenido o reducido por el ejercicio del control de la etapa de operación correspondiente.

- Establecer los límites críticos para los PCC.- Límites críticos son las tolerancias prescritas o predefinidas que se deben cumplir para asegurar que el PCC efectivamente controle el peligro correspondiente. Ejemplos de límites químicos son el pH, la concentración de sal, etcétera; límites físicos son el tiempo y la temperatura, entre otros; límites microbiológicos son el número de colonias; y límites sensoriales son las características organolépticas.

- Establecer procedimientos de monitoreo.- El monitoreo o vigilancia es la medida u observación efectuada en un PCC que demuestra que el proceso está funcionando dentro de los límites críticos. Es una de las partes más importantes del sistema HACCP y garantiza que el producto se elabora continuamente de manera segura.

- Establecer acciones correctivas.- Este elemento apunta hacia las medidas que deben adoptarse ante la ocurrencia de una situación de peligro durante el monitoreo de los PCC. Las acciones correctivas son los procedimientos que se deben aplicar en el caso de encontrar una desviación no aceptable de un PCC. 
- Establecer un sistema de registros.- Un sistema de registros de la información del plan HACCP es fundamental para demostrar que se ejecutan los procedimientos de monitoreo, las medidas correctivas y las verificaciones.

- Establecer procedimientos de verificación.- Este elemento se basa en métodos, procedimientos y pruebas o ensayos adicionales empleados para determinar si el sistema HACCP está operando de acuerdo con el diseño establecido, es decir, que es operativo (auditorías internas, inspección y ensayo, muestreo aleatorio, revisión de registros, validación de los límites críticos, etcétera).

- Certificación del sistema HACCP.- Parte de una preauditoría (opcional), auditoría de certificación y emisión del certificado. Las auditorías de seguimiento anuales son necesarias.

\subsection{Consecuencias del plan HACCP}

- Mejoran las condiciones higiénicas sanitarias en las plantas de procesamiento de productos para consumo humano.

- Se garantiza la calidad y sanidad de dichos productos frente al reto exportador.

- Mejora la relación costo-beneficio por reducción de costos, mayor aprovechamiento de los recursos y mejor precio de los productos.

- Reducción de los rechazos de productos por defectos.

- Incremento de la oferta exportable, mayor ingreso de divisas y mayores fuentes de trabajo.

- Sensibilización de la clase empresarial respecto de los beneficios del sistema HACCP.

\section{EL HACCP Y EL MODELO ISO}

El modelo ISO 9000, que incluye el HACCP, fue uno de los primeros pasos para incluir a este en el sistema ISO, cuyo enfoque era netamente preventivo y buscaba principalmente la inocuidad del alimento. Muchos se pronunciaron sobre el tema e indicaron que se dejaba de lado la calidad del alimento. Así, en setiembre del 2006 se publica la ISO 22000, que incluye la inocuidad y calidad del alimento. La ISO 9000 brinda una muy buena base para los requerimientos del sistema HACCP. La ISO 15161, guía publicada en noviembre del 2001 sobre 
la aplicación de la ISO 9001-2000 está dirigida a la industria de alimentos y bebidas. La ISO 22000, norma publicada en setiembre del 2005 , ayudará a los fabricantes de productos alimenticios en el uso apropiado de los principios del sistema HACCP. La 22000 tratará todos los aspectos de la calidad de los alimentos, mientras la 15161 se concentra exclusivamente en su inocuidad. En los gráficos 5 y 6 se presentan el modelo ISO 9001/2000 y su relación con las buenas prácticas de manufactura.

\section{Gráfico 5 \\ Sistema de gestión Modelo ISO 9001/2000}

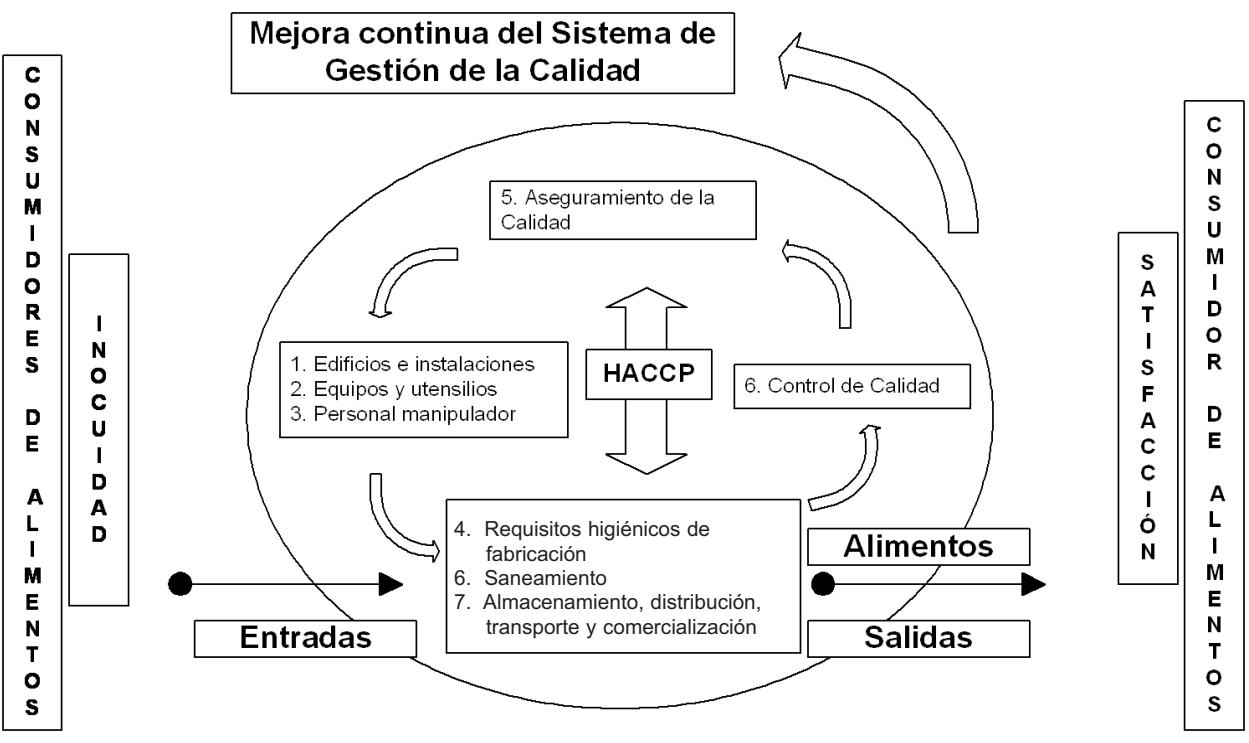

Gráfico 6

Relación entre BPA, BPM, HACCP e ISO

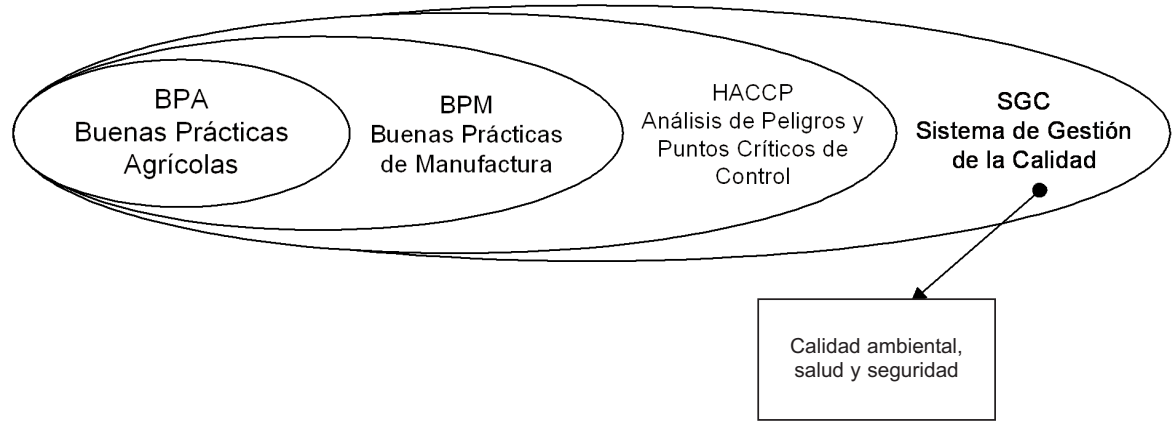




\section{ISO 22000:2005}

ISO 22000 e ISO/TS 22004 son resultantes del Comité de Trabajo (WG) 8 en materia de sistemas de gestión para seguridad de alimentos/alimentaria, e integrante del Comité Técnico ISO/TC 34. En la ISO 22000, además de los delegados de los países miembros de la Organización Internacional para la Estandarización ISO, participan la Comisión Codex Alimentarius, la Confederación de las Industrias de Alimentos y Bebidas de la Unión Europea (CIAA), la Iniciativa Seguridad de Alimentos, el Foro Internacional de Acreditación (IAF) y la Organización Mundial de Seguridad de Alimentos (WFSO).

La norma es aplicable a todos los agentes de la cadena alimentaria, desde los fabricantes de productos para la alimentación animal hasta los distribuidores de alimentos para consumo humano, incluyendo subcontratistas y organizaciones interrelacionadas (proveedores de equipos, envases, servicios de limpieza, aditivos e ingredientes). Su alcance es demostrar la capacidad de controlar peligros y lograr productos inocuos que satisfagan al cliente y cumplan exigencias legales así como planificar, diseñar, implementar, operar, mantener y actualizar el sistema de gestión de seguridad alimentaria encaminado a suministrar productos que demuestren que el alimento es seguro para el consumidor. Asimismo, evaluar los requisitos de los clientes en relación con la seguridad alimentaria y demostrar la conformidad con los alimentos; demostrar una comunicación efectiva con los clientes y otras partes interesadas a lo largo de la cadena alimentaria; asegurar que se cumpla con la política de seguridad alimentaria establecida; demostrar el cumplimiento a otras partes interesadas y obtener la certificación o reconocimiento de su sistema de gestión de seguridad alimentaria por entidades externas.

Otros documentos de referencia en la familia ISO 22000:2005:

- ISO/TS 22003*.

- ISO/TS 22004, especificación técnica.

- Documento de orientación y guía para ISO 22000.

- ISO/TS $22005^{*}$.

- Requisitos para trazabilidad en la cadena alimentaria.

- Principios generales y guías para diseño y desarrollo de sistema.

\footnotetext{
* Normativas en desarrollo.
} 
El contenido de la norma ISO 22000 tiene tres partes claramente diferenciadas:

- Requisito para buenas prácticas de fabricación o programa de prerrequisitos.

- Requisitos para HACCP de acuerdo con los principios HACCP enunciados en el Codex.

- Requisitos para un sistema de gestión.

\section{CERTIFICACIÓN DE PRODUCTOS AGROALIMENTARIOS E HIGIENE ALIMENTARIA}

\subsection{British Retail Consortium (BRC)}

La norma BRC para alimentos (British Retail Consortium) tiene como objetivo asegurar que sus proveedores cumplan con los requisitos que garanticen la salubridad de los alimentos. Es una organización comercial que representa el 90\% de la venta minorista en el Reino Unido. Los trabajos en la norma BRC empezaron en 1996, cuando los minoristas del Reino Unido se percataron de que en el tema de la seguridad alimentaria había varias ventajas para compartir la experiencia y juntos desarrollar sistemas sólidos.

\subsection{British Retail Consortium (BRC/IOP)}

El British Retail Consortium y el Instituto de Empaques (BRC/IOP) establecieron la norma que relaciona la producción de alimentos con la fabricación de material de envase y embalaje. La norma se divide en los siguientes capítulos: Sistema HACCP, Sistema de gestión de la calidad, Requisitos para la planta de producción, Control de la contaminación y personal.

\subsection{International Food Standard (IFS)}

La IFS es una norma creada por las grandes empresas de distribución alemanas y francesas que regula los sistemas de gestión de la calidad en empresas del sector de la alimentación, con el objetivo de lograr la máxima seguridad en los procesos de fabricación y manipulación de alimentos. 


\subsection{Safe Quality Foods-2000 (SOF-2000)}

El Programa SQF (Alimentos Sanos y de Calidad) es un protocolo de manejo de inocuidad y calidad de alimentos. El SQF 2000 tiene programas de soporte necesarios para cumplir sus objetivos, por tal razón considera la aplicación de ciertos prerrequisitos en su implementación: códigos de prácticas, estándares orgánicos como IFOAM, BRC (British Retail Consortium, Reino Unido), IFS (International Food Safety, Alemania), Eurepgap, Non-GMO, HACCP y GMP.

\subsection{La certificación orgánica}

La agricultura orgánica es una forma de agricultura sostenible. Su principal característica es que se dedica al cultivo, crianza y elaboración de productos alimenticios utilizando al máximo los recursos naturales y evitando el uso de agentes químicos o sintéticos. El objetivo de este sistema productivo es promover en el largo plazo el equilibrio sostenible de factores tanto ecológicos como económicos y sociales.

\subsection{La ley contra el bioterrorismo}

Es la ley dada en Estados Unidos, que incluye el registro de instalaciones alimenticias y exige que los alimentos que procesan, empacan y almacenan sean consumidos en ese país y deben registrarse ante la FDA. En cuanto a alimentos importados, la notificación previa exige que los embarques de alimentos sean notificados antes del arribo a Estados Unidos. La detención administrativa establece los procedimientos para emprender, con carácter de urgencia, acciones de detención de alimentos. Así también el establecimiento y mantenimiento de registros para determinar las fuentes inmediatas anteriores y los receptores inmediatos posteriores de los alimentos producidos, con el fin de lograr su trazabilidad.

\section{Buenas Prácticas Agrícolas Europeas (EUROGAP)}

Un grupo de empresarios europeos de la calidad y compradores de productos frescos creó en 1997 EUREP (Euro-Retailer Produce Working Group; en español se le conoce como Grupo de trabajo de minoristas de productos frescos). El objetivo de esta agrupación "es elevar los es- 
tándares sanitarios de la producción de fruta fresca y vegetales". En este grupo participan importantes cadenas de distribución minorista europea que desean establecer criterios técnicos para el producto o los productos que les interesa comprar. Los propósitos son buscar la confianza del consumidor a través de la calidad e inocuidad de los productos; respetar el medio ambiente, procurando mejorarlo, e incrementar la biodiversidad. Procurar el menor uso posible de los agroquímicos y su uso debe ser justificado por personal calificado. Se debe buscar la integración de la actividad agrícola con la naturaleza, el cuidado de la salud de los trabajadores, su seguridad y bienestar.

\section{Bussiness Alliance for Secure Commerce (BASC)}

Es una asociación sin fines de lucro que opera como un programa de cooperación voluntaria entre el sector empresarial, las autoridades aduaneras, las entidades gubernamentales y los organismos internacionales, para fomentar prácticas seguras en la cadena de suministros del comercio internacional de mercancías. Facilita la entrada de los productos nacionales a otros países, de acuerdo con convenios establecidos con el Buró de Aduanas y Protección Fronteriza (Custom and Border Protection, CBP) y otras aduanas en Europa y permite tener menor tiempo de almacenaje en los puertos de destino: las empresas certificadas con el sistema integral de gestión y administración de la seguridad (BASC), cuatro días aproximadamente; las empresas no certificadas, entre 8 y 12 días.

\section{BIBLIOGRAFÍA}

Certificaciones del Perú [en línea]. <http:// www.cerper.com/index.swf $>$.

Comisión para la Promoción de Exportaciones. "Normativas de Estados Unidos contra el Bioterrorismo" [en línea]. <http://www. prompex.gob.pe/Prompex/Documents/05776738-e9f8-4e22-98738a52f3248c14.pdf>.

Control Union World Group. "Main certification program" [en línea]. $<$ http://www.skalint.com>.

Departamento de Salud y Servicios Humanos de los Estados Unidos. "Guía de Preguntas y Respuestas sobre el Registro de Instala- 
ciones Alimenticias" [en línea]. <http:// www.cfsan.fda.gov/ $\sim$ acrobat/sfsbtreg.pdf>.

Departamento de Salud y Servicios Humanos de los Estados Unidos. "Lo que usted necesita saber sobre el registro de instalaciones alimenticias" [en línea]. <http://www.cfsan.fda.gov/ acrobat/ sfsbtreg.pdf $>$.

Dirección Nacional de Salud Ambiental. "Relación de normas legales del ámbito de Digesa" [en línea]. <http://www.digesa.sld.pe/ normas.htm>.

Eurepgap. "The Global Partnership for Safe and Sustainable Agriculture" [en línea]. <http://www.eurep.org/Languages/English/ index_html>.

Fennema, O. R. Introducción a la ciencia de los alimentos. Barcelona: Reverté, 1985.

Internacional Federation of Organic Agriculture Movements, IFOAM [en línea]. <http://www.ifoam.org>.

Ministerio de Agricultura del Perú. "Comisión Nacional de Productos Orgánicos" [en línea]. <http://www.minag.gob.pe/conapo2.shtml>.

Ministerio de Agricultura del Perú. "Guía práctica. Reglamento Técnico para los Productos Orgánicos" [en línea]. <http:// www.minag.gob.pe/boletines/ GuiaPracticaConapo.pdf $>$.

Proamazonía. "Gestión de la Calidad y BPA" [en línea]. Curso a distancia sobre gestión de la calidad y BPA. <http://www.proamazonia.gob.pe/bpa/introduccion.htm>.

SGS in Peru [en línea]. <http:// www.pe.sgs.com/es_pe/home_pe>.

Organización de las Naciones Unidas para la Alimentación y la Agricultura. "Agricultura orgánica" [en línea]. <http://www.fao.org/ unfao/bodies/coag/Coag15/X0075S.htm>.

US Food and Drug Administration (FDA). "Compliance Policy Guide" [en línea]. Hoja informativa sobre el registro de instalaciones alimenticias. <http://www. cfsan.fda.gov/ furls/cpgreg2.html>.

—. "Fact Sheet on FDA'S New Food Bioterrorism Regulation Final Rule: Administrative Detention" [en línea]. Hoja informativa 
sobre la Norma de Detención Administrativa. <http:// www.cfsan.fda.gov/ dms/fsbtac21.html>.

—. "Normativa propuesta: Establecimiento y Mantenimiento de Registros" [en línea]. Hoja informativa sobre la Norma de Establecimiento y Mantenimiento de Registros.<http:// www.cfsan. fda.gov/ dms/sfsbtac9.html>.

—. "Prior Notice of Imported Food Questions and Answers" [en línea]. Guía de Políticas de Cumplimiento sobre la Notificación Previa de Alimentos Importados. <http://www.cfsan.fda. gov/ pn/pnqagui2.html $>$.

—. "Rules and Regulations" [en línea]. Norma sobre la Detención Administrativa.<http://www.fda.gov/OHRMS/DOCKETS/98fr/0 4-12366.htm>.

— . "The Bioterrorism Act of 2002" [en línea]. Guía de Políticas de Cumplimiento sobre el Registro de Instalaciones Alimenticias. $<$ http://www.fda.gov/oc/bioterrorism/bioact.html>. 